\title{
ANALYSIS OF AGRICULTURAL MECHANIZATION IN ZANJAN PROVINCE, IRAN: APPLICATION OF SWOT-AHP METHOD
}

\author{
Mostafa Nazari Nasab \\ Department of agricultural mechanization \\ Science and Research Branch, Islamic Azad University \\ Tehran, Iran \\ E-mail: nazarinasab.m@srbiau.ac.ir \\ Majid Azizi \\ Department of Wood \& Paper Sciences and Technology \\ University of Tehran \\ Karaj, Iran \\ E-mail: mazizi@ut.ac.ir
}

\begin{abstract}
Decision making and strategy selection to agricultural development in underdeveloped and developing countries is always like as major model which can be get on the capital of their country. In these countries Strategy selection is regardless to the characteristics of different regions, there is similar problem in Iran. This research was part of major study that wants to analysis agricultural development of Zanjan province in Iran by using system analysis methods. Zanjan province is in northwestern of Iran, Which has seven cities (Zanjan, Abhar, Eijroud, Tarom, Mahneshan, Khodabande, and Khoramdare). By use SWOT (Strengths, Weaknesses, Opportunities and Threats) analysis for agricultural mechanization of Zanjan province, we found four factors which used as criteria in AHP method. Hierarchy model of this research has goal, factors, sub factors and alternatives. The goal is to select the best city based on the agricultural development. The criteria and sub criteria are SWOT factors. Alternatives are cities of Zanjan province. Local weights were calculated for criteria and alternatives and then overall weights were calculated for only alternatives. Overall weights of alternatives were obtained: Khodabande 0.290, Khoramdare 0.137, Abhar 0.135, Eijroud 0.124, Zanjan 0.120, Mahneshan 0.115, and Tarom 0.081. Results showed that Khodabande has suitable status based to aspects of agricultural development and it is better than other cities also Results of this study showed that governments politics are effective to development of agriculture in different cities.
\end{abstract}

Keywords: agricultural mechanization, AHP method, SWOT analysis, AHP-SWOT hybrid method. 


\section{Introduction}

These days a lot of energy is consuming to do agricultural operation and mechanization of agriculture. Development criteria such as energy ration and energy efficiency have special politics which necessary in: waste prevention, estimation of needs, optimum consumption, and education in case of accurate use of energy and... . Energy using of farm machinery consist three parts, energy consumption before entering to farm for example manufacturing step, energy consumption inside the farm for example tillage and planting, energy consumption outside of farm for example transportation. we can optimize energy consumption by taking strategies in every three parts. in Iran agricultural development activities done without consideration of specific conditions of various region and decision making done similar for all of them. Distribution of agricultural machinery is not effective on agricultural development because entering the machine into farm without recognizing it increases the risks, for example investment risk, soil erosion, product reduction and timeline costs.

In this study, we attempt to assess the effect of different conditions to rate the cities of Zanjan province regard to agricultural development perspective. We use the strengths, weaknesses, opportunities, and threats (SWOT) approach in combination with analytic hierarchy process (AHP) to achieve this issue. The SWOT-AHP allows us to classify the cities in the hierarchical structure, evaluate factors in the pair compressions and quantify the relative importance of criteria in order to rate the SWOT factors. We utilize preference data involved agricultural mechanization usage in Zanjan province. Although SWOT-AHP is a Common method in strategic planning literature but it is the first time that someone applied it in Iranian agriculture. Our wish is to bring the system analysis methods in the Iranian agriculture for improve the decision making process.

\section{Literature Review}

Reviewing the literature of SWOT analysis or AHP technique reveals that the joining of these two methods is a quite novel approach, and there are only a few papers concerning this methodology:

Kurttila in his study whit subject utilizing the analytic hierarchy process (AHP) in SWOT analysis - a hybrid method and its application to a forest - certification case, they used AHP for rating of SWOT factors.

Yuksel and Dagdeviren in their study, researched on the using the analytical network process (ANP) in SWOT analysis, their study results showed SWOT analysis cannot determine important of factors analytical network process can do it and ANP can complete SWOT analysis.

Shrestha in his study, researched on the exploring the potential for silvopasture adoption in south-central Florida: an application of SWOT-AHP method, they plus weight of each of SWOT factors then results showed various regions has different conditions.

Zaerpour in his study, researched on the Make to order or make to stock decision by a novel hybrid approach, they examination some hybrid method that one of them was SWOT-AHP method. Their study showed use hybrid method can give us correct answer and it better than use one of the methods as single (Zaerpour et al., 2008). 


\section{Hypotheses/Objectives}

\section{Hypotheses:}

1. Different factors are effective on the development of agricultural mechanization in Zanjan province.

2. Different regions of Zanjan province have different properties based on their development of agricultural mechanization.

3. AHP-SWOT hybrid method can help us to achieve accurate strategic planning.

\section{Objectives:}

1. Rank the cities of Zanjan province based on agricultural mechanization.

2. SWOT analysis of agricultural mechanization and use these results as criteria on the AHP structure in Zanjan province.

\section{Research Design/Methodology}

This method includes several steps. First we use some indexes to determine statistical community. 2nd we calculate sample size of statistical community. 3rd we used from SWOT analysis for determine strengths, weaknesses, opportunities and threats of agriculture then select three important case for every factors between SWOT analysis result. We use these three important cases for every factor as sub factors. 4th we form hierarchy which the goal is in upstairs of this hierarchy then factors and sub factors is in middle of hierarchy and alternatives is in the bottom. We used Daier and Forman theory to form hierarchy. They suggested hierarchy can form as this structure: goal, factors, and sub factors and alternatives. 5th we ask from agricultural experts to answer existing pair comparisons matrix to determine local weights and overall weights.

\section{Data/Model Analysis}

AHP method has different types of hierarchy. In designing hierarchy there is no Special law. Our hierarchy includes goal, factors, sub factors and alternatives. Goal is above of hierarchy. In this study goal is 'determine important city between cities of Zanjan province according to agricultural development approach'. SWOT factors are our factors in this hierarchy then we have four factors. This time we have three sub factors for every criteria. Alternatives are below in shape. In this study our alternatives are cities of Zanjan province. We start to calculate after hierarchy has been formed. We calculate local weights and overall weights. Show hierarchy model in the fig1.

The local weights calculate in three stages. First we formed pair comparisons matrix and then we get statistical community which help to fill and complete the matrixes. We will calculate geometric mean after completed the matrix by statistical community because we need a unit answers. We have one criteria matrix, four sub criteria matrixes and 12 alternatives matrixes for this model so we have 17 matrixes in the overall. We have to complete all of the matrixes and then enter this data in to the Expert Choice software in addition we used participants table in this software for direct 
input of data. The second step is calculating inconsistently index. We calculate inconsistently index after completed pair comparison matrix. It is acceptable if inconsistently index is less than 0.10 but it is not when it is more than 0.10 so we have to change decision until inconsistently index be less than 0.10. In this study we got inconsistently index by EC software. The third step is calculation of local weights and overall weights.

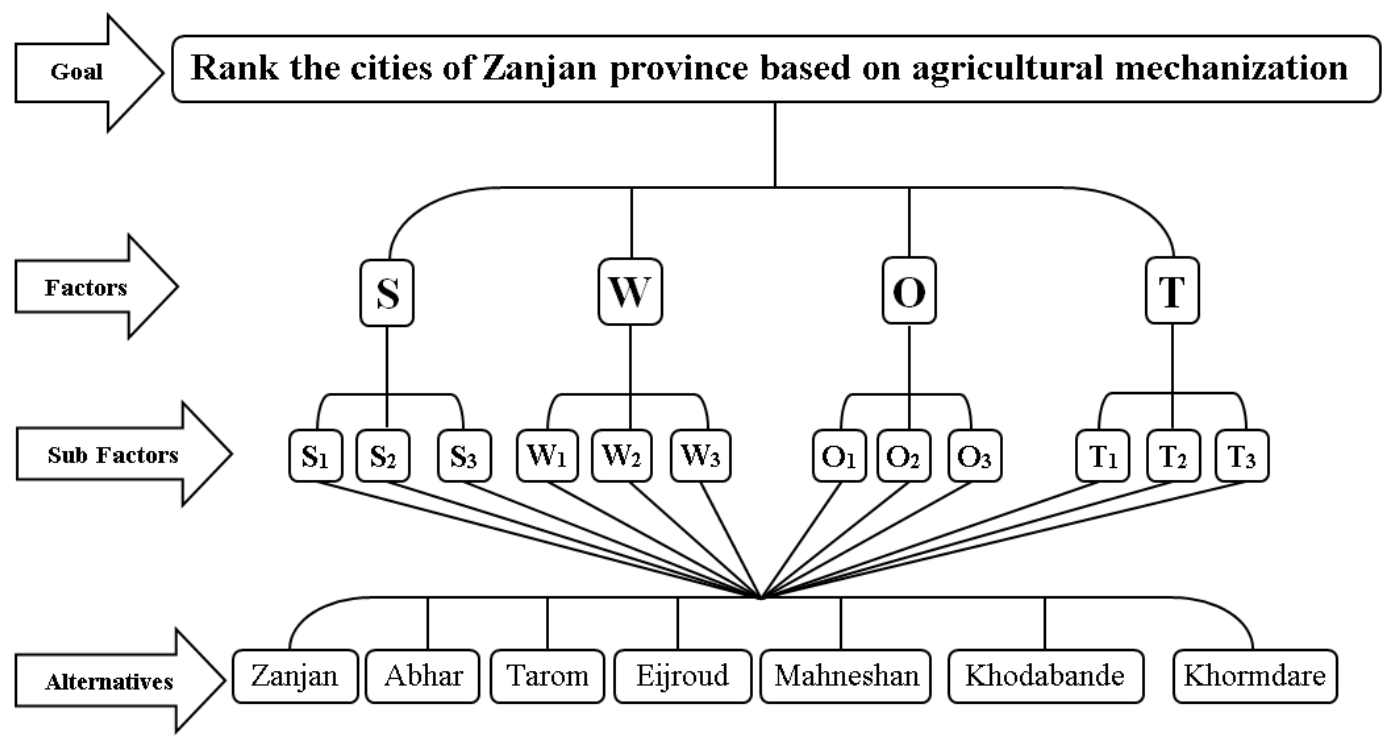

fig1. Hierarchy of this study

In this study we have four factors (SWOT factors). We form pair comparisons matrix for factors and then we ask agricultural experts to fill this pair comparisons matrix. In table4 showed geometric mean of answers.

Table4. Pair comparisons matrix for factors

\begin{tabular}{|c|c|c|c|c|}
\hline & strengths & weaknesses & Opportunities & Threat \\
\hline strengths & 1 & $1 / 4$ & $1 / 2$ & $1 / 2$ \\
\hline weaknesses & 4 & 1 & 5 & 3 \\
\hline Opportunities & 2 & $1 / 5$ & 1 & 2 \\
\hline Threat & 2 & $1 / 3$ & $1 / 2$ & 1 \\
\hline
\end{tabular}

We calculate inconsistently index after complete pair comparisons matrix. Inconsistently index for pair comparisons matrix of factors is 0.07 so it is acceptable. We calculate local weight in this stage. In table5 showed factors local weight.

Table5. Local weight of factors

\begin{tabular}{|c|c|}
\hline factors & Local weight \\
\hline Strength & 0.098 \\
Weakness & 0.562 \\
Opportunity & 0.190 \\
Threat & 0.150 \\
\hline
\end{tabular}


Above result showed weakness factor is more important than another factors for statistical community. Sum of negative factors is 0.712 and sum of positive factors is 0.288 . We can understand that our statistical community do not risk because value of negative factors is very much for them.

\section{1 sensitivity analysis}

We used dynamic analysis and performance analysis for sensitivity analysis which showed in fig2, fig3.

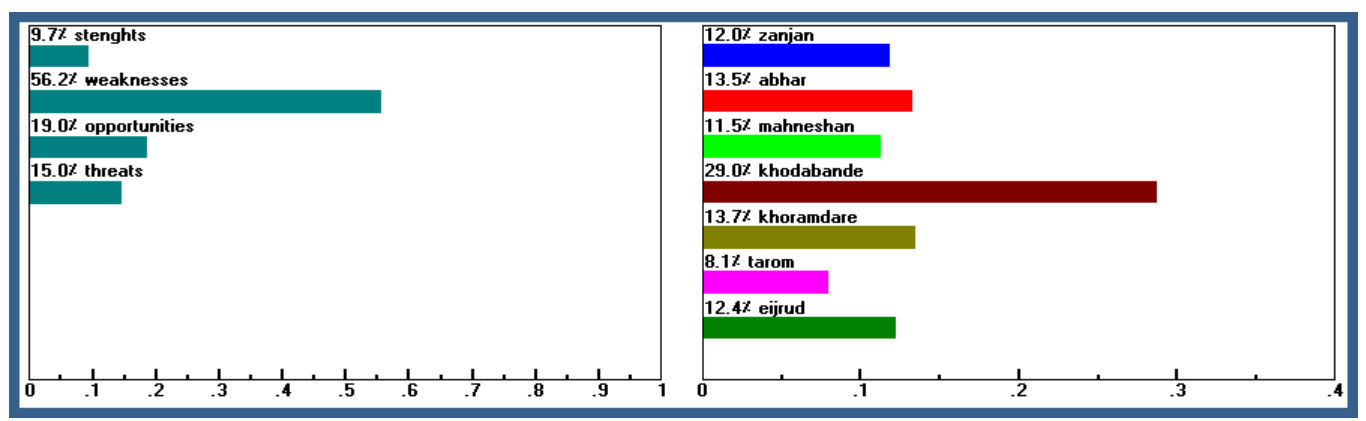

Fig2. Dynamic analysis

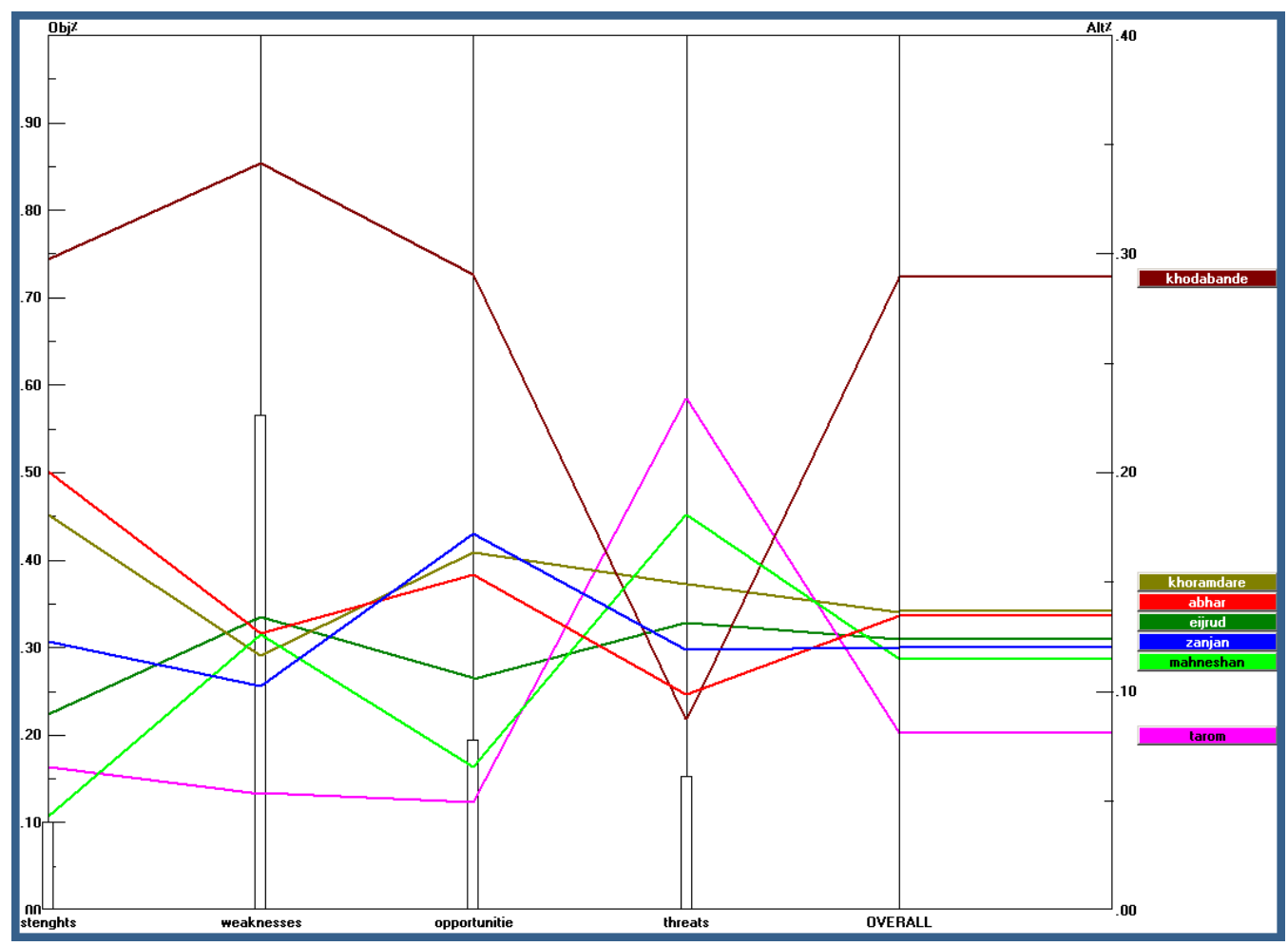

Fig3. Performance analysis

In the current situation Results of dynamic analysis showed that Khodabande is the best city but the value of SWOT factors (criteria) might be changed by implementation of the governments new strategies in future, and thus rank of cities will change. Dynamic 
analysis showed in fig2. Results of performance analysis showed that Tarom is In contrast with Khodabande because Khodabande is first regard to three criteria (SWO) but Tarom is approximately the last one and Tarom is first regard to Threats factor but Khodabande is the last. In addition performance analysis showed that results classified the cities in 3 groups, first Khodabande, 2nd includes 5 cities (Zanjan, Abhar, Eijroud, Mahneshan and Khoramdare), 3rd Tarom. Performance analysis showed in fig3.

\section{Limitations}

We feel these limitations:

1. In the large and real model, number of Questions (pair comparisons) is very much and this case has negative effect on the participants. So we have to find a method for reduce the number of questions in pair comparisons.

2. AHP and ANP methods are suitable tools for decisions making and strategy selection in agriculture, agricultural development and agricultural mechanization, but it is not enough because it can't do system analysis when system is dynamic as well as static, so we have to find a method to combine these methods with system dynamics methods.

\section{Conclusions}

We used SWOT-AHP method to evaluation of agricultural development in Zanjan province. Zanjan province has seven cities while each of the cities has different properties. This method has two main parts. First part is SWOT analysis. We got common properties in different cities by use SWOT analysis and then select three important cases for each of factors. Second part is AHP method. We have ranked the cities regard to SWOT factors by use AHP method. This method helps us to understanding agricultural development of Zanjan province better. We showed value of

each city by numeric value according to agricultural development. SWOT-AHP method is suitable method for agricultural development research.

\section{Reference}

1. Ali ahmadi, E., \& Fathollah, M., \& Tajeddin, I. (2003). A comprehensive approach to strategic management. Tolide danesh publication.

2. Ghodsi pour, S. H. (2008). Analytic hierarchy process AHP. Polly techniques university publication.

3. kurttila, M., \& pesonen, M., \& kangas, J., \& kajanus, M. (2000). Utilizing the analytic hierarchy process (AHP) in SWOT analysis - a hybrid method and its application to a forest-certification case. Forest policy and Economics, 1 (1), 41-52.

4. Shrestha, PK., \& Alavalapati, JRR., \& Kalmbacher, RS. (2004). Exploring the potential for silvopasture adoption in south-central Florida: an application of SWOTAHP method. Agricultural systems, 81 (3), 185-199.

5. yuksel, I., \& Dagdeviren, M. (2007). Using the analytical network process (ANP) in SWOT analysis: a case study for a textile firm. Information sciences, 177 (16), 33643382 . 